\title{
Avaliação do Estado Imune de Mulheres em Idade Reprodutiva em Relação ao Virus da Rubéola
}

Evaluation of the Immune Status of Women in Reproductive Age Regarding Rubella Virus

Sylvia Maria Dantas Fonseca, Valéria Cristina Ribeiro Dantas, Marianna Toscano Dantas, José Veríssimo Fernandes

\section{RESUMO}

Objetivo: avaliar o estado imune de mulheres em idade reprodutiva, em relação ao vírus da rubéola. Métodos: foram analisadas aliquotas de soros de 2.243 mulheres na faixa etária dos 15 aos 45 anos (média de 26 anos), residentes na área urbana de Natal, RN, para avaliação do estado imune em relação ao virus da rubéola. Do total das mulheres examinadas, 1.170 $(52,1 \%)$ eram gestantes e 1.073 (47,9\%) não-gestantes. Foi pesquisada a presença de anticorpos das classes IgM e IgG no soro de todas as pacientes, empregando-se a técnica de ELISA em fase sólida, revelada mediante fluorescência (ELFA).

Resultados: do total das pacientes analisadas, 1.632 se apresentaram imunes e 611 se mostraram suscetiveis ao virus da rubéola. Os indices médios de imunidade e de suscetibilidade observados nos 4 anos estudados foram 73,0 e 27,0\% respectivamente. No grupo das mulheres consideradas suscetiveis, 14,5\% não apresentaram qualquer sinal da presença de anticorpos contra o vírus da rubéola, 7,7\% apresentaram anticorpos da classe IgM isoladamente e em 4,8\% delas foi detectada a presença simultânea de anticorpos IgM e IgG.

Conclusão: os achados revelaram que uma parcela significativa da população feminina de Natal, em idade reprodutiva, ainda se encontra suscetivel ao vírus da rubéola, revelando a existência real de risco de infecção congênita por esse patógeno. Recomenda-se a vacinação seletiva dessas mulheres contra a rubéola, como forma segura de prevenir as manifestações relacionadas à sindrome de rubéola congênita.

PALAVRAS-CHAVE: Rubéola. Gravidez normal. Pré-natal. Vacinação.

\section{Introdução}

A rubéola é uma doença viral, exantemática aguda, autolimitada, de evolução benigna, que

Departamento de Microbiologia e Parasitologia

Universidade Federal do Rio Grande do Norte e

Centro de Patologia Clínica de Natal -RN

Correspondência:

José Veríssimo Fernandes

Departamento de Microbiologia da

Universidade Federal do Rio Grande do Norte

Lagoa Nova

59072-970 - Natal - RN atinge preferencialmente crianças e adultos jovens, ocorrendo muitas vezes na forma assintomática ${ }^{6,9,12}$. O vírus da rubéola infecta exclusivamente a espécie humana, de forma que a manutenção desse patógeno na natureza depende da existência, na comunidade, de indivíduos suscetiveis ${ }^{4}$. Em comunidades urbanas, a rubéola apresenta caráter endêmico, ocorrendo, entretanto, surtos epidêmicos a intervalos mais ou menos regulares. Pouco se sabe sobre o comportamento dessa enfermidade nas comunidades rurais e em populações isoladas ${ }^{11}$.

Uma extensa epidemia de rubéola foi 
registrada nos Estados Unidos, em 1964 e 1965, com a ocorrência de 1.800 .000 casos da doença, dos quais 250.000 em mulheres grávidas, ocasionando dezenas de milhares de natimortos e de crianças nascidas a termo, mas apresentando anomalias conhecidas como sindrome de rubéola congênita $(\mathrm{SRC})^{10}$. Outras epidemias dessa virose foram registradas em diversas partes do mundo, conforme descrito por Cutts et al. ${ }^{3}$, com indices variáveis de manifestações de SRC. Em Singapura em 1986, o índice encontrado foi de 1,5 por 1000 crianças nascidas vivas, em Israel, 1972, esse indice foi de 1,7, no Panamá, 1986, 2,2 e no Sri Lanka, 1994, 0,93.

Do ponto de vista patológico, a rubéola teria pouca importância, não fosse a possibilidade de ocorrência da infecção congênita, decorrente da infecção materna durante os três primeiros meses de gestação tendo em vista a ação teratogênica do vírus. Na infecção congênita, pode haver a invasão do complexo placenta-feto pelo vírus, com disseminação pelos tecidos embrionários, podendo resultar no aborto espontâneo ou no nascimento a termo de crianças apresentando manifestações relacionadas à $\mathrm{SRC}^{1,3-5,11,14,15}$.

A ação teratogênica do virus da rubéola sobre o organismo do feto se faz por meio de dois mecanismos: a infecção crônica, que pode se prolongar por vários meses após o nascimento, e a inibição da atividade mitótica das células embrionárias, afetando o crescimento e a diferenciação celular, podendo resultar na ausência completa de órgãos ou na formação defeituosa destes $^{5,16}$. A infecção do feto durante o primeiro trimestre da gestação aumenta em $50 \%$ o risco de ocorrência de aborto espontâneo e causa um percentual ainda mais elevado de anomalias relacionadas com a $\mathrm{SRC}^{3}$.

As manifestações da SRC podem ser transitórias, tais como: hepato-esplenomegalia, púrpura trombocitopênica e ictericia, ou permanentes, entre estas catarata, surdez sensorial, anormalidades cardiovasculares, displasia da retina, coriorretinite, microcefalia, lesão cerebral e retardo mental, ou ainda manifestações tardias como é o caso da diabetes mellitus $\mathrm{s}^{3,4,9,15}$.

$\mathrm{O}$ risco absoluto da ocorrência de SRC varia amplamente em diferentes estudos, provavelmente em função da idade em que as crianças são examinadas, tendo em vista que algumas das seqüelas são transitórias, desaparecendo após algum tempo ao passo que outras só aparecem tardiamente ${ }^{3}$. Estudando 269 crianças nascidas de mães que foram infectadas pelo virus da rubéola durante a gestação, Miller et al. ${ }^{13}$, demonstraram que o risco de infecção congênita foi de $81 \%$, com ocorrência de malformações em $69 \%$ do casos, quando a infecção materna se deu no primeiro trimestre da gestação.

Em um estudo desenvolvido por Cutts et al. ${ }^{3}$ no qual se avaliou o grau de suscetibilidade de mulheres em idade reprodutiva, em 45 países em desenvolvimento, demonstrou-se que em 13 desses países a proporção de mulheres suscetiveis foi menor que $10 \%$, mas em 20 deles esse índice variou de 10 a $24 \%$ e nos outros 12 países o índice de suscetibilidade foi maior ou igual a $25 \%$.

Halstead et al. ${ }^{8}$ em um estudo epidemiológico realizado no Havaí, envolvendo adolescentes e adultos, demonstraram que a porcentagem de individuos suscetiveis à rubéola naquele estado americano variou de 25 a $50 \%$ da população examinada. No Brasil, vários estudos baseados na pesquisa de anticorpos em gestantes ou mulheres em idade reprodutiva, realizados em diversas regiões do país, mostram que pelo menos $20 \%$ das mulheres dessa faixa etária ainda são suscetiveis à rubéola ${ }^{5,8,9,14}$.

O presente trabalho teve como objetivo investigar o grau de suscetibilidade ao virus da rubéola, de um grupo de mulheres em idade reprodutiva, que procuraram o nosso serviço no periodo de 1994 a 1997 para verificar o seu estado imune em relação a essa enfermidade, tendo em vista a suspeita clínica da infecção por esse vírus. Esse tipo de abordagem se reveste da maior relevância, não apenas pelo fato de permitir esclarecer o estado imune das pacientes, mas principalmente por revelar a proporção de mulheres em idade fértil que ainda se encontram suscetiveis ao virus da rubéola. Essa informação permite orientar os órgãos encarregados da saúde pública, na definição de possiveis campanhas de vacinação contra a rubéola, visando a prevenção da infecção congênita e conseqüentemente dos seus efeitos tão indesejáveis.

\section{Pacientes e Métodos}

\section{Casuistica}

Foram analisadas alíquotas de soros de um grupo de 2.243 mulheres, das quais 1.170 eram gestantes e 1.073 não-gestantes. Todas estavam na faixa etária de 15 a 45 anos com média de idade de 26 anos e eram residentes na área urbana da cidade de Natal (RN). Essas pacientes foram encaminhadas ao Centro de Patologia Clínica, no período compreendido entre janeiro de 1994 a dezembro de 1997, para avaliação do seu estado imune em relação ao vírus da rubéola, tendo em 
vista a existência de suspeita clínica da infecção por esse patógeno.

Antes da coleta de sangue para a obtenção do soro, foi solicitado a todas as mulheres que concordaram em participar do estudo, que respondessem a um inquérito epidemiológico, realizado por meio de um questionário padronizado, a partir do qual foram obtidas informações tais como: idade, estado de gravidez ou não, história pregressa de rubéola ou de doença exantemática, contato com indivíduos portadores da doença, vacinação contra essa enfermidade e dados clínicos.

\section{Análise laboratorial}

De cada paciente foi obtida uma única amostra de soro, na qual foi pesquisada, em reações separadas, a presença de anticorpos das classes IgM e IgG, específicos para o vírus da rubéola. O método empregado foi o ensaio imunoenzimático (ELISA) em fase sólida, com leitura final por meio de fluorescência utilizando a técnica denominada ELFA ("enzyme linked fluorescent assay"), realizada utilizando o sistema Vidas-Rub, da Bio Mérieux. Trata-se de um ensaio quantitativo, automatizado, em que a leitura da reação é feita pela quantificação da fluorescência emitida, utilizando-se filtro de 450 $\mathrm{nm}$. A intensidade de fluorescência emitida é proporcional à quantidade de anticorpos presentes na amostra de soro pesquisada. A concentração de anticorpos da classe IgM na amostra é expressa na forma de índice de sinalização de fluorescência, ao passo que a concentração de anticorpos da classe IgG é expressa na forma de unidades internacionais por mililitro.

Foram consideradas negativas, para anticorpos da classe IgM, as pacientes cujos soros apresentaram índices de sinalização de fluorescência menores que 0,8 , e positivas aquelas em que esses indices foram iguais ou superiores a 1,2. Com relação aos anticorpos da classe IgG, foram consideradas negativas as pacientes cujos soros apresentaram menos de 10
$\mathrm{UI} / \mathrm{ml}$, e positivas aquelas que apresentaram valores de leitura iguais ou superiores a $15 \mathrm{UI} /$ $\mathrm{ml}$. Para efeito de interpretação dos resultados obtidos, foram consideradas suscetiveis ao vírus da rubéola, dentro da sua faixa etária, todas as mulheres que não apresentaram qualquer sinal da presença de anticorpos para o vírus da rubéola e aquelas nas quais foi detectada a presença de anticorpos da classe IgM, seja isoladamente ou em associação com anticorpos da classe IgG.

\section{Resultados}

Foram examinadas alíquotas de soro de 313 mulheres durante o ano de 1994, 521 em 1995, 703 em 1996 e 706 em 1997, perfazendo um total de 2.243 pacientes pesquisadas. Desse total, 1.170 mulheres, o equivalente a $52,1 \%$ da amostra, eram gestantes e $1.073(47,9 \%)$ não-gestantes. No grupo das mulheres gestantes, $252(11,2 \%)$ se mostraram suscetiveis e 918 (40,9\%) se apresentaram imunes ao vírus da rubéola. As porcentagens de suscetibilidade à doença nesse grupo, nos 4 anos pesquisados, variaram de 10,8 a $11,5 \%$, apresentando um índice médio de suscetibilidade de $11,2 \%$, ao passo que as porcentagens de mulheres imunes desse mesmo grupo variaram de 39,8 a $42,4 \%$, sendo que o índice médio de imunidade encontrado nos 4 anos pesquisados foi de $41,0 \%$ do total da amostra.

No grupo das mulheres não-gestantes, 359 $(16,0 \%)$ se apresentaram suscetiveis e $714(31,8 \%)$ se mostraram imunes ao virus da rubéola. As porcentagens de susceptibilidade à doença nesse grupo variaram de 14,4 a $17,9 \%$, nos 4 anos pesquisados, apresentando um índice médio de susceptibilidade de $15,8 \%$ do total das pacientes examinadas, ao passo que as porcentagens de mulheres imunes ao vírus, nesse mesmo grupo, variaram de 30,9 a $33,2 \%$. O índice médio de imunidade encontrado foi de $32,0 \%$ do total da amostra (Tabela 1).

Tabela 1 - Estado imune de mulheres em idade reprodutiva, gestantes e não-gestantes, em relação ao vírus da rubéola

\begin{tabular}{cccccccccc}
\hline & \multicolumn{3}{c}{ Gestantes } & \multicolumn{5}{c}{ Não-gestantes } \\
\hline Ano & Imunes & $\%$ & Suscetíveis & $\%$ & Imunes & $\%$ & Suscetíveis & $\%$ & Total \\
1994 & 129 & 41,2 & 35 & 11,2 & 104 & 33,2 & 45 & 14,4 & 313 \\
1995 & 221 & 42,4 & 56 & 10,8 & 161 & 30,9 & 83 & 15,9 & 521 \\
1996 & 280 & 39,8 & 80 & 11,4 & 217 & 30,9 & 126 & 17,9 & 703 \\
1997 & 288 & 40,8 & 81 & 11,5 & 232 & 32,8 & 105 & 14,9 \\
$\%$ (média) & - & 41,0 & - & 11,2 & - & 32,0 & - & 106 \\
Total & 918 & 40,9 & 252 & 11,3 & 714 & 31,8 & 359 & 16,8 \\
\hline
\end{tabular}


Constatou-se que, no geral, isto é, sem separar as mulheres gestantes das não-gestantes, um total de 339 pacientes, o que representa $15,1 \%$ da amostra, não apresentaram qualquer sinal da presença de anticorpos dirigidos contra o vírus da rubéola. As porcentagens de mulheres nessa condição, no decorrer dos 4 anos estudados, variaram de 12,1 a $18,8 \%$, com média de $14,5 \%$ do total de pacientes examinadas. Observou-se ainda que 158 pacientes, equivalente a $7,0 \%$ da amostra, apresentaram anticorpos da classe IgM isoladamente. As porcentagens de mulheres nessa condição variaram de 3,5 a $11,2 \%$. Além disso, em 114 mulheres $(5,1 \%)$ foi detectada a presença simultânea de anticorpos das classes IgM e IgG. As porcentagens de pacientes nessa condição variaram de 2,2 a $6,7 \%$, no período estudado, com média de $4,8 \%$ do total da amostra pesquisada (Tabela 2).

Tabela 2 - Estado imune de mulheres em idade reprodutiva, em relação à rubéola, discriminado de acordo com o tipo de resposta apresentada.

\begin{tabular}{|c|c|c|c|c|c|c|c|}
\hline \multicolumn{8}{|c|}{ Suscetibilidade para o vírus da rubéola } \\
\hline Ano & $\mathrm{n}$ & Sem Ac & $\%$ & $\lg M$ & $\%$ & $\lg M+\lg G$ & $\%$ \\
\hline 1994 & 313 & 38 & 12,1 & 35 & 11,2 & 7 & 2,3 \\
\hline 1996 & 703 & 100 & 14,2 & 59 & 8,4 & 47 & 6,7 \\
\hline 1997 & 706 & 133 & 18,8 & 25 & 3,5 & 28 & 4,0 \\
\hline$\%$ média & - & - & 14,5 & - & 7,7 & - & 4,8 \\
\hline
\end{tabular}

Ac $=$ Anticorpos

Quandosse consideraram apenas as condições de imunidade ou de susceptibilidade ao vírus da rubéola, sem especificar o tipo de resposta apresentada pelas pacientes, observou-se que no grupo das mulheres classificadas como suscetiveis ao virus da rubéola, num total de 611 pacientes, o equivalente a $27,2 \%$ da amostra, as porcentagens de susceptibilidade a esse patógeno variaram de 25,6 a $29,3 \%$, nos 4 anos estudados, apresentando um indice médio de susceptibilidade de $27,0 \%$ do total de mulheres pesquisadas. No grupo das mulheres classificadas como imunes ao virus da rubéola, isto é, aquelas que apresentaram somente anticorpos da classe IgG, num total de 1.632 pacientes, o que representa $72,8 \%$ da amostra, observou-se que as porcentagens de mulheres nessa condição variaram de 70,7 a $74,4 \%$, nos 4 anos pesquisados, apresentando índice médio de imunidade de 73,0\% do total da amostra (Tabela 3).

Tabela 3 - Estado imune de um grupo de mulheres em idade reprodutiva em relação à rubéola.

\begin{tabular}{lccccc}
\hline \multicolumn{5}{c}{ Estado imune para rubéola } \\
\hline Ano & $\mathrm{n}$ & Imunes & $\%$ & Suscetíveis & $\%$ \\
\hline 1994 & 313 & 233 & 74,4 & 80 & 25,6 \\
1995 & 521 & 382 & 73,3 & 139 & 26,7 \\
1996 & 703 & 497 & 70,7 & 206 & 29,3 \\
1997 & 706 & 520 & 73,7 & 186 & 26,3 \\
$\%$ média & & & 73,0 & & 27,0 \\
Total & 2.243 & 1.632 & 72,8 & 611 & 27,2 \\
\hline
\end{tabular}

\section{Discussão}

Nesse estudo, apresentamos os resultados de uma avaliação do estado imune para o vírus da rubéola em uma parcela da população feminina da cidade de Natal, em idade reprodutiva, na faixa etária dos 15 aos 45 anos, média de 26 anos, que foram encaminhadas ao nosso laboratório com suspeita clínica de infecção pelo vírus da rubéola. A porcentagem elevada de mulheres grávidas na amostra estudada (52.1\%) reflete a preocupação tanto das pacientes como dos médicos com a possibilidade de ocorrência da infecção por esse virus durante o período de gestação.

Consideraram-se como suscetiveis as mulheres que não apresentaram anticorpos contra o virus da rubéola e aquelas que apresentaram anticorpos da classe IgM, isoladamente ou em associação com anticorpos da classe IgG. Por outro lado, foram classificadas na condição de imunes as mulheres que apresentaram somente anticorpos da classe IgG, específicos para o vírus da rubéola. Esse critério foi adotado tendo em vista que a presença de anticorpos IgM, seja isolada ou simultaneamente com anticorpos da classe IgG, indica a ocorrência de infecção recente. Como nosso objetivo foi determinar o grau de susceptibilidade apresentado pelas mulheres examinadas, dentro de uma faixa etária estabelecida, em que a unidade de referência foi o periodo de um ano, as mulheres que desenvolveram a infecção pouco 
tempo antes de serem examinadas foram classificadas como suscetíveis à doença, dentro da sua faixa etária.

Analisando-se o estado imune das mulheres pesquisadas, de acordo com a especificação do tipo de resposta apresentada, constatou-se que em média $14,5 \%$ das mulheres pesquisadas não apresentaram qualquer sinal da presença de anticorpos dirigidos contra o vírus da rubéola, $7,7 \%$ delas apresentaram anticorpos da classe IgM isoladamente e em $4,8 \%$ do total da amostra, foi detectada a presença simultânea de anticorpos das classes IgM e IgG. O percentual relativamente elevado de mulheres com a presença de anticorpos IgM, $12,5 \%$ do total da amostra estudada, justificase, provavelmente, devido ao fato de grande parte dessas pacientes terem procurado os serviços médicos durante o período em que encontravam-se sob a suspeita clínica de infecção pelo vírus da rubéola, que em muitos casos foi confirmada sorologicamente, mediante a detecção de anticorpos IgM, específicos para o referido patógeno, comprovando, assim, a ocorrência de infecção recente.

Quando, no entanto, o estado imune das mulheres pesquisadas foi analisado de uma forma global, isto é, sem fazer distinção entre grávidas e não-grávidas, verificou-se que $73,0 \%$ das pacientes se apresentaram imunes à rubéola, conforme demonstrado sorologicamente pela presença isolada de anticorpos da classe IgG. No entanto, $27,0 \%$ do total da amostra estudada se mostrou suscetivel à rubéola, tendo em vista a ausência total de anticorpos dirigidos contra esse patógeno ou a presença de anticorpos da classe IgM, seja isolada ou simultaneamente com anticorpos da classe IgG.

Os dados obtidos nesse estudo mostram que o índice médio de suscetibilidade à rubéola apresentado pelas mulheres de Natal está um pouco acima dos encontrados em cidades de outras regiões do país, em mulheres de faixas etárias semelhantes. Na cidade de São Paulo, um estudo realizado por Cotillo $^{2}$ revelou a existência de um indice de suscetibilidade à rubéola de $22,8 \%$, em um grupo de mulheres gestantes. No Rio de Janeiro, Schatzmayr e Mesquita ${ }^{16}$ encontraram indice de suscetibilidade de 20\%. Já em Porto Alegre, Estrella ${ }^{5}$ encontrou um índice de suscetibilidade à rubéola de 19,0\% em mulheres na faixa etária de 20 aos 40 anos. Por outro lado, esses resultados confirmam o índice de suscetibilidade encontrado em um outro estudo com características semelhantes realizado em Natal, por Fonseca et al. ${ }^{7}$ no qual o índice apresentado foi de 26,0\%. Além disso, o indice de suscetibilidade encontrado nesse estudo está em perfeita concordância com os indices de suscetibilidade para a rubéola, encontrados por Cutts et al. ${ }^{3}$ em um grupo de 12 países em desenvolvimento. Os achados mostram que uma parcela considerável da população feminina de Natal, em idade reprodutiva, ainda se encontra suscetível ao vírus da rubéola, o que representa um alvo em potencial para esse patógeno.

Considerando-se a ação teratogênica do vírus da rubéola, um índice de suscetibilidade tão elevado a esse patógeno, em mulheres da faixa etária estudada, deve ser motivo de preocupação por parte das autoridades sanitárias, tendo em vista a possibilidade da ocorrência da infecção congênita e das conseqüências dela decorrentes. Assim sendo, justifica-se a realização de campanhas de vacinação seletiva dessas mulheres contra a rubéola, como forma segura de prevenir a infecção congênita por esse vírus e conseqüentemente impedir a ocorrência das manifestações associadas à síndrome da rubéola congênita.

\section{SUMMARY}

Purpose: to evaluate the immune status of women in reproductive age regarding the rubella virus.

Methods: 2,243 samples of serum from women in the age range of 15 to 45 years, with an average of 26 years, living in the urban area of Natal, RN were analyzed, to evaluate the immune status in regard to rubella virus. Of these women, 1,170 (52.1\%) were pregnant and 1,073 (47.9\%) were not. IgM and IgG antibodies were determined, using solid phase ELISA and fluorescence (ELFA) techniques.

Results: of the 2,243 women, 1,632 showed immunity to rubella virus and 611 did not, therefore being susceptible to this virus. The rates of immunity and susceptibility in this study were $73.0 \%$ and $27.0 \%$, respectively. In 611 susceptible woman, $14.5 \%$ did not present antibodies against rubella virus, $7.7 \%$ had only IgM antibody and $4.8 \%$ had $\operatorname{IgG}$ and IgM antibodies.

Conclusions: our findings show that a significant group of women from Natal, in reproductive age, is still susceptible to rubella virus, indicating the risk of congenital infection by this pathogen. We advise the selective vaccination of those women against rubella to prevent clinical manifestations related to the congenital form of the disease.

KEY WORDS: Rubella. Immune status regarding rubella. 


\section{Referências}

1. Angeles DM, Gutiérrez G, Garcilazo J. Estudio immunologico da la rubeola en un gupo de alumnas de la Universidad Iberoamericana, Ciudad de Mexico. Bol oficina Sanit Panam 1971;71: 401-10.

2. Cotillo ZLG. Anticorpos neutralizantes contra rubéola num grupo de gestantes de São Paulo. Rev Inst Med Trop São Paulo 1968; 2: 29-43.

3. Cutts FT, Robertson SE, Diaz-Ortega JL, Samuel R. Control of rubella and congenital rubella syndrome (CRS) in developing countries, part 1: burden of disease from CRS. World Health Organization, 1997;75: 55-68.

4. de Paulino IL, Komaid JÁ, de Castagnaro NR, Raya JM. Nivel de anticuerpos contra rubéola y evaluacion de la immunidad por vacunación, Tucuman, Argentina. Bol oficina Sanit Panam 1979; 86: 529-33.

5. Estrella VMA. Anticorpos para rubéola em Porto Alegre, em mulheres de 20 a 40 anos. Rev Inst Med Trop São Paulo 1974;16: 337-40.

6. Farhat CK. Rubéola . Clin Pediatr, 1980; 5:31-5.

7. Fonseca SMD, Dantas MT, Fernandes JV. Infecção pelo vírus da rubéola em um segmento da população feminina em idade fértil residente em Natal, RN. Rev Med MG 1997;7: 14-7.
8. Halstead SB, Diwan AR, ODA AI. Susceptibility to rubella among adolescents and adults in Hawai. JAMA 1983;210: 1881-3.

9. Ishak R, Leão JE, Cardoso DDP, Fernandes OFI. Prevalência de anticorpos para a rubéola em um segmento da população feminina, gestante ou não em Goiânia. Rev Inst Med Trop São Paulo 1981;23:139-42.

10.Levi GC. Rubéola. Rev Bras Med 1984; 41: 263-6.

11.Linhares AC, Macedo O, Santos EO. Prevalência de anticorpos para o vírus da rubéola em uma comunidade indigena isolada ao norte do Pará, Brasil. Rev Latinoam Microbiol 1983; 25: 131-6.

12.Marquez A, Zapata MT. Comportamiento epidemiológico de la rubeola em la provincia de Cordoba, Argentina. Bol oficina Sanit Panam 1984; 97:14-25.

13.Miller E, Cradok-Watson JE, Pollock TM. Consequences of confirmed maternal rubella at successive stages of pregnancy. Lancet 1982; 2: 781-4.

14.Nogueira RM, Schatzmayr HG, Lopes IR. Aspectos laboratoriais e epidemiológicos de infecções por rubeóla na cidade do Rio de Janeiro. Rev Soc Bras Med Trop 1984;10: 107-11.

15.Pereira MB. Cardiopatias congênitas: Perspectiva pediátrica. Pediatr Mod, 1992; 28: 416-20.

16.Schatzmayr HG, Mesquita JA. Papel do laboratório de análise clínica no controle de casos da da infecção pela rubéola. Bol Epidemiol Ministério Saúde 1972; 4:10. 